\title{
LA CONSTRUCCIÓN DE LA CIUDAD A TRAVÉS DE IMAGINARIOS COLECTIVOS: LA NARRATIVA DE LA CASA DE ADOBE Y LA EX-ADUANA
}

LEONARDO ANDRÉS MORENO TOLEDANO

ÉRIKA ANASTACIA ROGEL VILLALBA

\section{RESUMEN}

1

1 presente ensayo plantea el potencial de la ciudad como generador de narrativas, a partir de los imaginarios colectivos. En particular, presenta la consideración de la existencia de lugares históricos que quedan fuera de la narrativa de los habitantes de la ciudad, mientras otros se vuelven parte importante de la historia de la misma. Primeramente este documento presenta un panorama teórico sobre la ciudad como texto y como narrativa, para posteriormente exponer como ejemplo dos casos: la Casa de Adobe y la Ex-Aduana en Ciudad Juárez, Chihuahua.

Palabras clave: imaginarios colectivos, ciudad, narrativa, memoria, Ciudad Juárez.

\section{ABSTRACT}

The present essay explores the city's potential as a narrative generator coming from it. Specifically analyses how places that 
hold a historical relevance to the city may not bee seen as a part of the narrative of its inhabitants. We shall present a theoretical panorama about the city as a text and as a narrative to give an example of two cases: Casa de adobe and Ex-Aduana in Ciudad Juárez, Chihuahua.

Keywords: imaginaries collective, city, narrative, memory, Ciudad Juárez.

\section{INTRODUCCIÓN}

El tiempo y el espacio han sido categorías constantemente cuestionadas en cuanto a su existencia real y, sin embargo, han estado presentes en el pensamiento humano en toda imaginación, representación y medición del universo. Según Mora (2014):

Si reconocemos que, en el surgimiento mismo del lenguaje, y en la propia conformación de las sociedades, tiempo y espacio permiten nombrar, ordenar, clasificar, discriminar y jerarquizar la realidad que nos circunda para hacerla comunicable, entonces la pluralidad de visiones y de razonamientos puede ser vista como una buena muestra de la diversidad de maneras en que nos relacionamos con el mundo (p. 2).

Sin embargo, la construcción de lo que reconocemos como verdadero -lo real- no necesariamente es una construcción propia, se encuentra mediado por un conjunto de historias, relatos desarrollados en el tiempo; crónicas, cuentos, narraciones, algunas veces vivos a través de numerosas generaciones, y otras, adoptados desde culturas diversas. Algunos construidos con fines retóricos y otros de ellos, sin ninguna intención aparente. Empero, es a partir de esas historias que construimos nuestras identidades y entendemos nuestro entorno. Un ejemplo de lo anterior en el contexto mexicano, puede ser observado en la constitución del discurso de la Revolución mexicana, la cual fue objeto de distintas interpretaciones a la manera de una narrativa de carácter 
temporal, es decir, un concepto cuyos vértices han transitado de una figura utópica a una mítica. Misma que, a través de diversos relatos, logró fincarse como una ideología nacional desde distintas dimensiones socioculturales: la historiografía, la memoria cultural y la retórica política.

Dentro del contexto de las narraciones, la Toma de Ciudad Juárez, Chihuahua, jugó un papel preponderante en la construcción de lo que entenderíamos por México durante el siglo XX. Sin embargo, la construcción de la historia no se limita únicamente a los relatos orales, por lo que el presente trabajo pretende explicar cómo los objetos, en este caso las edificaciones, juegan un rol importante en nuestra memoria colectiva en la construcción de nuestra realidad.

Para explicar lo anterior, dividiremos el presente escrito en tres partes. En la primera, presentaremos la importancia que juegan el relato y la memoria en la construcción de nuestros imaginarios. Más adelante, expondremos la ciudad, y más específicamente lo construido, como constructora de relatos. Finalmente, describiremos la manera en la que las narraciones ayudan a construir un imaginario a partir de lo construido. Esto, a través de una comparación de dos edificaciones emblemáticas de la época: la Casa de Adobe y la Ex-Aduana.

\section{NARRATIVA Y MEMORIA}

En su Introducción al análisis estructural de los relatos, Roland Barthes (1970) comienza explicando que:

El relato puede ser soportado por el lenguaje articulado, oral o escrito, por la imagen fija o móvil, por el gesto y por la combinación ordenada de todas estas sustancias; está presente en el mito, la leyenda, el cuento, la fábula, la novela, la epopeya, la historia, la tragedia, el drama, la comedia, la pantomima, el cuadro pintado, el vitral, el cine, las tiras cómicas, las noticias policiales, la conversación. Además de estas formas casi infinitas, el relato está presente en todos los tiempos, en todos los lugares, en todas las sociedades; 
el relato comienza con la historia misma de la humanidad; no hay ni ha habido jamás en parte alguna un pueblo sin relatos; todas las clases, todos los grupos humanos, tienen sus relatos y muy a menudo estos relatos son saboreados en común por hombres de cultura diversa e incluso opuesta (p. 9).

Siguiendo a Barthes (1970) podemos asumir que los relatos, se encuentran presentes en cualquier lugar, en cualquier cultura, en cualquier sociedad y que no se limitan a la palabra escrita u oralidad, sino que trascienden los objetos y los espacios. Asimismo, los relatos no solo representan historias, sino que podemos, incluso, decir que, a partir de ellos, se construye nuestro mundo; a partir de imaginarios, de creencias compartidas que se sustentan en una especie de complicidad entre los diversos actores sociales.

Estas creencias, parafraseando a John Thompson (1998), se conforman en narrativas, a través de las cuales los sujetos podemos tejer explicaciones coherentes, tanto de nosotros mismos como del mundo que nos rodea. De este modo, la narrativa permite construir una historia, por vaga e imprecisa que resulte, que dé forma y sentido a quienes somos y consecuentemente, cuál podría ser nuestro futuro (p. 273). A partir de estas creencias compartidas, se crea lo que actualmente se denomina memoria colectiva. Misma que puede ser definida como

un fenómeno social, importante y complejo, en el cual los recuerdos particulares entran en una dinámica que sólo compete a la comunidad, pues es en su seno que son confrontados, completados e incluso corregidos, con otros recuerdos. Con ello, el grupo accede a la convicción de que aquello que se guarda en la memoria es veraz (Romero, 2009, p. 23).

Cabe mencionar que los mecanismos de la memoria, según Henri Bergson (1896), comienzan con la percepción. Para Bergson (1896), la percepción está determinada por la acción; vemos lo que nos interesa y esto se encuentra condicionado a nuestra memoria, a lo que conocemos, y por tanto, excluimos muchas cosas 
del mundo en las que no pensamos actuar. Para Bergson (1896) "conscious perception signifies choice, and consciousness mainly consists in this practical discernment. The diverse perceptions of the same object, given by my different senses, will not, then, when put together, reconstruct the complete image of the object" (p. 47). Para Bergson (1896) no existe la percepción pura, sino que esta se encuentra siempre mediada por la memoria.

Ahora bien, en relación con la memoria, Bergson (1896) sostiene que existen dos formas: la primera es la que se desarrolla a partir de la repetición:

I study a lesson, and in order to learn it by heart, I read it a first time, accentuating every line; I then repeat it a certain number of times. At each repetition, there is progress; the words are more and more linked together, and at last make a continuous whole. When that moment comes, it is said that I know my lesson by heart, that it is imprinted on my memory (p. 89). [Asimismo, añade que] the memory of the lesson, which is remembered in the sense of learnt by heart, has all the marks of a habit. Like a habit, it is acquired by the repetition of the same effort. Like a habit, it demands first a decomposition and then a recomposition of the whole action (p. 90).

Como se comentó, Bergson (1896) sostiene que también existe otra forma de la memoria: aquella mediante la cual guardamos eventos que son recordados a través de una "imagen" que nos hacemos de los mismos, y que vienen a nuestra mente en algún momento en particular cuando algo nos hace "recordarlos".

Bergson (1896) explica esta diferencia de la siguiente manera:

Following to the end this fundamental distinction, we are confronted by two different memories theoretically independent. The first records, in the form of memory-images, all the events of our daily life as they occur in time; it neglects no detail; it leaves to each fact, to each gesture, its place and date. Regardless of utility or of practical application, it stores up the past by the mere necessity of its own nature. By this memory is made possible the intelligent, or 
rather intellectual, recognition of a perception already experienced; in it we take refuge every time that, in the search for a particular image, we remount the slope of our past. But every perception is prolonged into a nascent action; and while the images are taking their place and order in this memory, the movements, which continue them, modify the organism, and create in the body new dispositions towards action. Thus, is gradually formed an experience of an entirely different order, which accumulates within the body, a series of mechanisms wound up and ready, with reactions to external stimuli ever more numerous and more varied, and answers ready prepared to an ever-growing number of possible solicitations. We become conscious of these mechanisms as they come into play; and this consciousness of a whole past of efforts stored up in the present is indeed also a memory, but a memory profoundly different from the first, always bent upon action, seated in the present and looking only to the future (p. 93).

Así, como expone Seguí de la Riva (año), el "relato es narración, cuento, descripción del conocimiento de un acontecer. El relato es la manera de uso lingüístico mediante la cual declaro lo que recuerdo como vivido. El modo de ser de la memoria” (p. 1).

\section{CIUDAD Y NARRATIVA}

En el apartado anterior, hicimos énfasis en que los relatos pueden ser encontrados en cualquier lugar y que conforman de manera esencial nuestro mundo, a través de la memoria colectiva. Barthes (1970) explica que todo discurso (conjunto de frase) tiene sus unidades, gramática y código propio (p. 12).

De acuerdo con lo anterior, podemos asumir que todo conjunto significativo de formas, sean estas signos lingüísticos en papel o conjuntos de edificios y calles en la ciudad, puede considerarse como una estructura gramatical. Es decir, conjuntos de reglas de operación que deben ser entendidas, tanto por quien construye el relato como por el lector del mismo. Esto es lo que Genette define como el rol del narrador y el rol del lector. 
Es común entender las ciudades como textos, cuyos caracteres son las vías públicas y los edificios, que pueden ser leídos de maneras precisas por aquellos que conocen sus historias. Pero también, es general pensar que las ciudades son testimonios estratificados de diversas dinámicas del poder que no dejan de murmurar historias inaudibles que todos los humanos intentan adivinar (Seguí de la Riva, (2006), p. 4).

Asimismo, agrega que:

Tratamos la arquitectura con palabras, hablando y escribiendo sobre este arte que nos remite a los edificios, que son los artefactos que envuelven nuestro vivir cotidianizado. Incorporamos los edificios en nuestras experiencias actuando en ellos, comportándonos en relación a ellos, disimulando la solidez de sus límites construidos como si no estuvieran, ubicando en su interior la memoria de nuestro pasado protegido. Con los edificios no se habla, aunque nunca dejan de dar que hablar. Tratamos con los otros vinculándolos a los edificios que frecuentan, a las ciudades donde desarrollan su transcurrir (p. 1).

Así entonces, podemos entender la ciudad desde la narrativa de dos formas. Por una parte, como un conjunto de acciones desarrolladas por los actores sociales que pueden ser contadas, y por otra, desde los objetos diseñados, considerados como contenedores del pasado, como guardianes de memorias colectivas y formadores de identidad.

En el presente trabajo nos abocaremos a la segunda, a los objetos diseñados; en este caso, los edificios y su papel como generadores de relatos, si bien no por ellos mismos, sí por las percepciones y representaciones de los diversos actores sociales en determinado contexto temporal.

Seguí de la Riva (2006) explica que

cualquier edificación que se considere es un escenario que permite ciertos comportamientos (usos) que se pueden conjeturar narra- 
tivamente, ajustados a las características organizativas, ambientales y ubicativas, que la propia arquitectura determina. Los edificios de la arquitectura son contenedores de historias (p. 3).

Sin embargo, cabe mencionar que no todas las edificaciones cuentan con la misma importancia narrativa y algunos edificios tienen un valor mayor en la generación de memorias colectivas; tal es el caso de los edificios históricos, los monumentos o aquelos lugares que se convierten en hitos, debido a las narrativas que surgen de ellos.

Por ello, es importante establecer que la construcción de los relatos, incluyendo aquellos que emanan a partir de las representaciones colectivas de las edificaciones, depende de lo que Todorov et al. (1970) definen como los procedimientos del discurso en los que se cuenta el tiempo del relato, es decir, la relación entre el tiempo de la historia y el del discurso; los aspectos del relato, es decir, la manera en la que la historia es percibida por el narrador; y los modos del relato, es decir, el tipo de discurso utilizado por el narrador para contar el relato (p. 174).

\section{DIÉGESIS DE LA CASA DE ADOBE Y LA EX-ADUANA EN CIUDAD JUÁREZ}

Geográficamente, Ciudad Juárez se encuentra situada en el norte de México, en el estado de Chihuahua, a orillas del río Bravo. Al norte, colinda con territorio estadounidense, particularmente con la ciudad de El Paso, Texas. Por su población de alrededor de 1320000 habitantes en 2010, es la ciudad más poblada del estado de Chihuahua y la octava zona metropolitana más grande del país.

Sin embargo, no siempre ha sido así. Anteriormente llamada Paso del Norte, se encontraba, en el momento de su fundación, en 1659, muchos kilómetros al sur del territorio estadounidense y no fue sino hasta 1848, con la pérdida de más de la mitad del territorio, que se convirtió en frontera.

El primer momento histórico, después de la fundación de la ciudad en 1659, fue la llegada del ferrocarril en 1884, lo que per- 
mitió mejorar la comunicación entre Paso del Norte y el resto del país. No obstante, la comunicación continuaba siendo únicamente de norte a sur, mientras que por el lado americano la ciudad de El Paso, Texas, se encontraba conectada con diversos puntos de Estados Unidos, por lo que era considerada como una metrópoli internacional.

En 1885 se concedió la franquicia de la zona libre, debido a la importancia que cobró la franja fronteriza con Estados Unidos, aunado a la llegada del ferrocarril y la solicitud del gobierno para impulsar la economía local, lo cual permitió un importante crecimiento comercial y que, además, influyó para que Paso del Norte tomara el aspecto de ciudad. Para reconocer dicho progreso, en 1888 se decretó el cambio de nombre de Paso del Norte a Ciudad Juárez.

Unos años después, Ciudad Juárez ocupó un lugar importante en el movimiento revolucionario de 1910 y, tal vez, ningún acontecer individual de su pasado pueda compararse en importancia con la Toma de Ciudad Juárez, operación militar de la Revolución mexicana que, en buena medida, definió el curso de aquel conflicto. Primero, porque la revolución resulta, sin lugar a dudas, un movimiento central para la comprensión de lo que actualmente es nuestro país, ya que, como se ha hecho notar, no se trató únicamente de un cambio de régimen de gobierno, sino de una verdadera reconfiguración de lo que los mexicanos entendíamos sobre nosotros mismos. En segundo lugar, porque, incluso, desde antes de que la ciudad fuera capturada por las fuerzas revolucionarias, la idea misma de su control ya había adquirido una gran importancia simbólica, derivada de las evidentes ventajas económicas y militares que su captura acarrearía. De manera que el movimiento revolucionario cambió radicalmente con posterioridad a la Toma de Ciudad Juárez, y es gracias a la renuncia de Porfirio Díaz, consecuencia directa de la ocupación de esta ciudad fronteriza, que la conflagración pasa a sus etapas subsecuentes, hasta dar forma al gran proyecto social que habría de definir al México del siglo XX (Duarte, 2011, p. 4). 
Pues según yo pienso, compañero, debemos lanzarnos al ataque, porque la verdad es que toda la gente nos tacharía de cobardes al considerar que nosotros, después de tantos días de permanecer aquí con un propósito, nos retirábamos sin hacer nada. Creo que por dignidad de hombres revolucionarios debemos arriesgarnos al ataque (Solares, 2011, p. 7).

Y le plantea la estrategia: mandar a algunos hombres a provocar a los federales y luego apersonarse para defender a los suyos:

Y de esta manera -continúa Villa-, paso a paso, iremos encendiendo la mecha hasta que ya no sea posible contener nuestra gente, que, como usted, sabe, anda ardorosa y propuesta a la toma de Ciudad Juárez. Una vez los ánimos en ese estado, ¿qué podemos hacer nosotros, compañero? Manifestamos al señor Presidente que la cosa ya no tiene remedio, y que no hay más que organizar nuestras fuerzas y proceder de modo decidido al asalto y toma de la población, para alcanzar al final la victoria o la muerte. Entonces él, viendo las circunstancias expuestas de esa manera, no tendrá otra opción que acceder a nuestros deseos. ¿Qué le parece, compañero?

\section{PASCUAL OROZCO LE RESPONDE, LACÓNICO: “ME PARECE BIEN” (P. 7).}

¿Qué hubiera sido de la revolución si Villa y Orozco acatan las órdenes de Madero? No es posible saberlo, pero lo cierto es que la desobediencia de los dos combatientes, le dio al movimiento su primera y más significativa victoria, pues gracias a ella fue posible lograr, por fin, la renuncia del dictador Díaz.

La Revolución mexicana de 1910 fue narrada por múltiples narradores y una de sus características principales, es que fue la primera revolución que sería "registrada" con fotografías e imágenes reales por los diarios norteamericanos y los periódicos más importantes de la época, así como por el incipiente "juguete" que representaban las cámaras cinematográficas. Puede decirse que la batalla de Ciudad Juárez fue la primera acción ofensiva "me- 
diática" difundida por los medios de comunicación, en ese entonces modernos y a la mano: la fotografía y el cine como nuevas extensiones del ojo y la memoria (McLuhan, 1994). De ahí la gran repercusión popular que en esos momentos iniciales tuvo la imagen de Francisco I. Madero, "quien era plenamente consciente de la relevancia de aprovechar esos instrumentos a favor de la causa revolucionaria" (Solares, [2011], p. 7).

Como puede apreciarse en los párrafos anteriores, la Revolución mexicana puede verse como un conjunto de relatos unidos que generan una panorámica de lo que fue el movimiento armado, a partir de ciertos imaginarios colectivos que derivaron en la creación de una memoria colectiva y una identidad, en este caso nacionalista.

Pero volviendo al terreno de lo construido, de las edificaciones, dos de ellas jugaron un papel protagónico en las diversas imágenes que narraron los acontecimientos de la Toma de Ciudad Juárez. La primera, la llamada Casa de Adobe, centro de reunión de los jefes revolucionarios y albergue improvisado de la familia Madero.

Allí estaban, en plena canícula de mayo, acampados a la orilla del río Bravo y mirando las altas chimeneas de la ASARCO o las casas del "otro lado". Decidieron que ningún jefe, por más respetado o temido que fuese, los haría desistir: habían llegado para atacar al ejército en Ciudad Juárez y lo iban a hacer (Mejía et al., 2011, p. 8). 
Figuras 1 y 2 . Imágenes de la casa de adobe. ${ }^{1}$
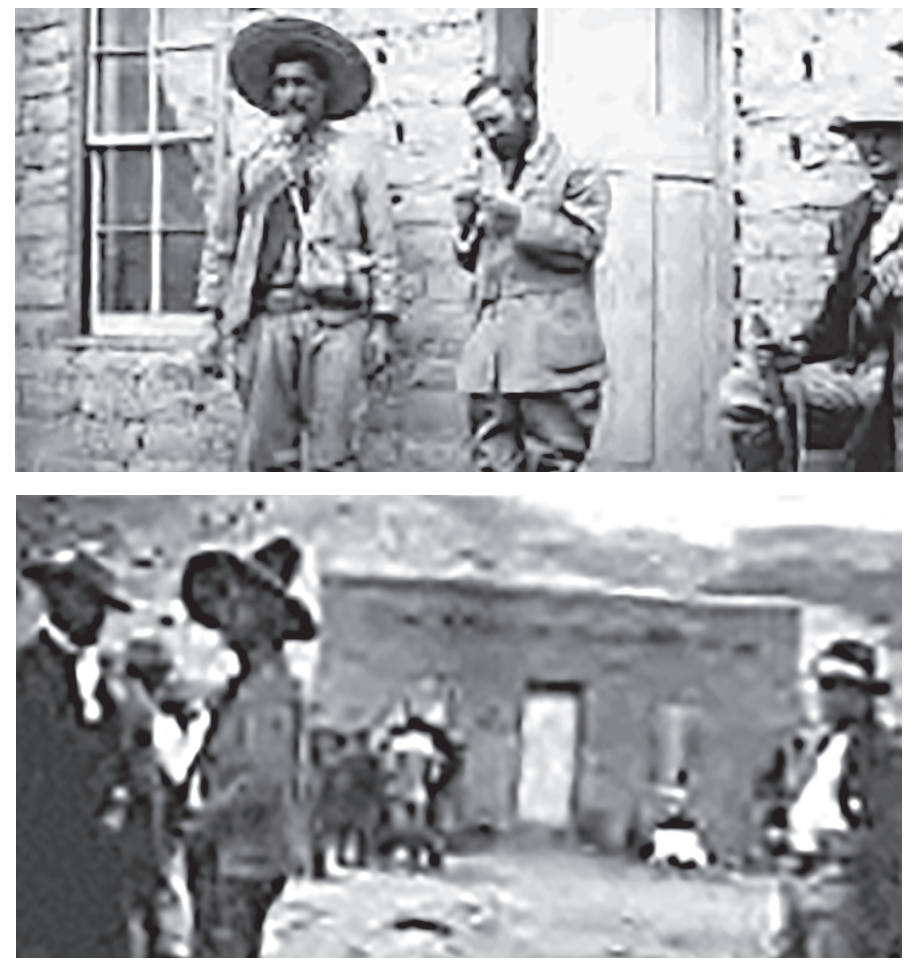

Figura 3. Fotografía del primer encuentro de jefes del ejército revolucionario; al fondo: la Casa de Adobe.

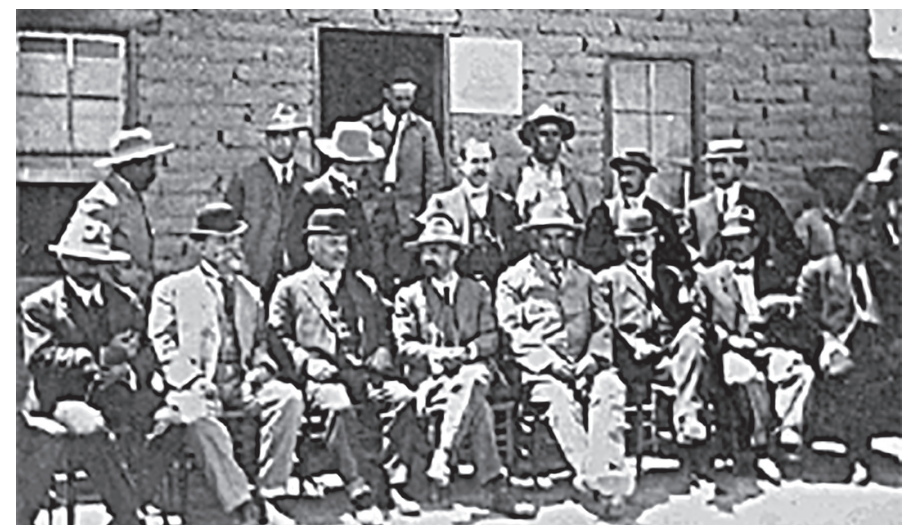

1 Todas las imágenes, a excepción de las particularmente señaladas, provienen del libro La Toma de Ciudad Juárez: una historia en imágenes. Mayo de 1911. 
La segunda, el edificio de la Ex-Aduana, localizado en la avenida principal de la ciudad (16 de Septiembre), y sitio por donde pasó el ejército revolucionario en su entrada triunfal por la victoria de la Toma de Ciudad Juárez.

Figura 4. Entrada triunfal de los revolucionarios por la calle Del Comercio (hoy avenida 16 de Septiembre); a la derecha, se aprecia el edificio de la Ex-Aduana.

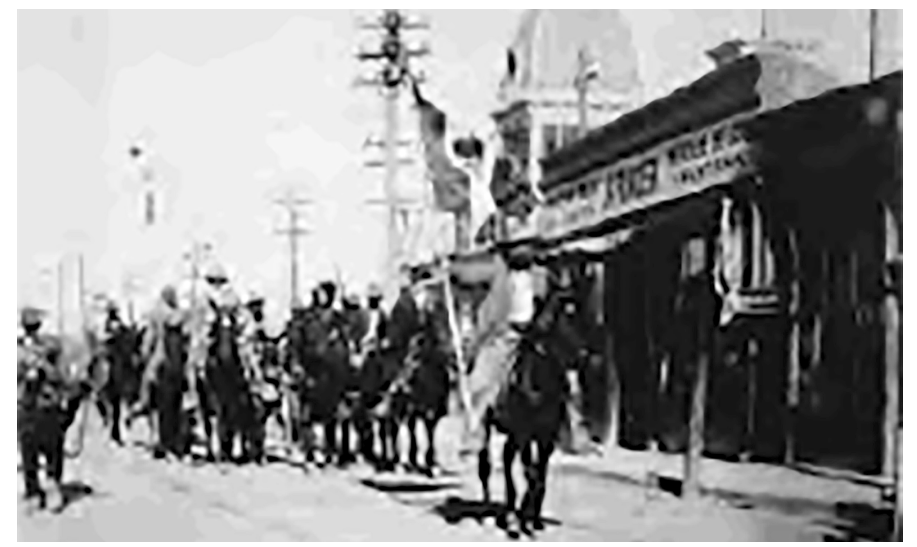

Figura 5. Vista de la calle Del Comercio; a la izquierda, el edificio de la Ex-Aduana.

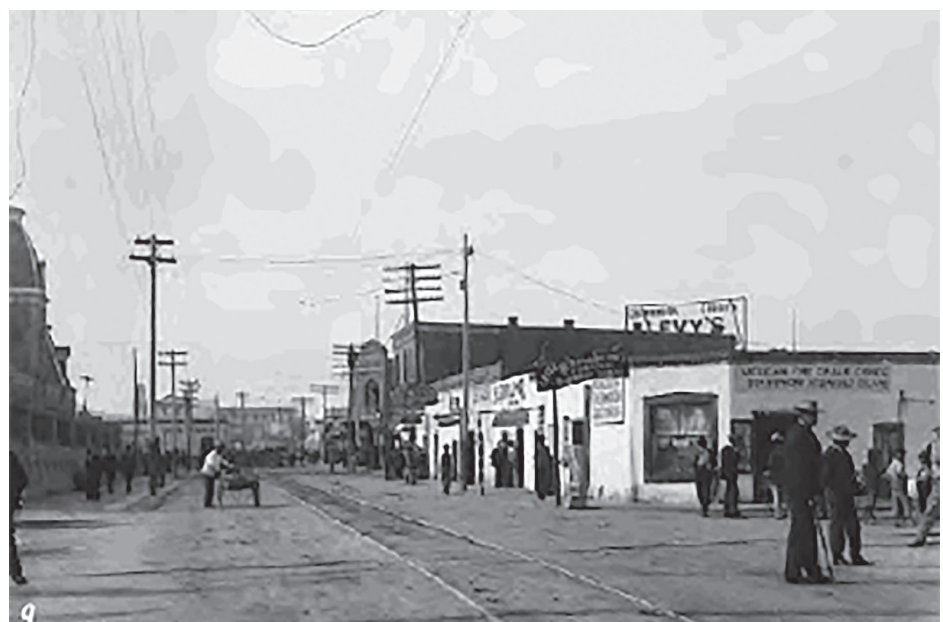


Figura 6. Vista del edificio de la Ex-Aduana de Ciudad Juárez. ${ }^{2}$

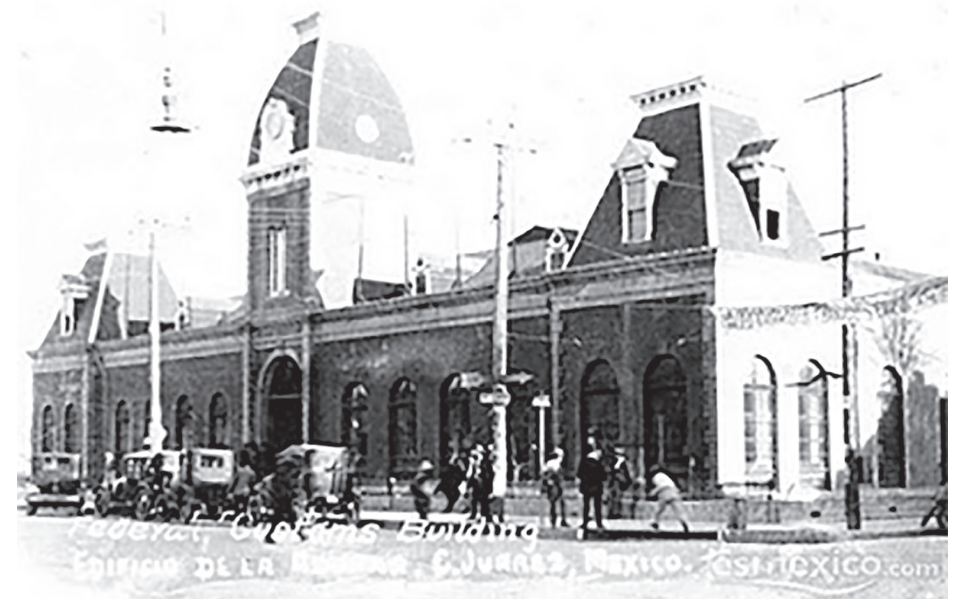

Es importante recordar los procedimientos del discurso de Todorov et al. (1970), en cuyo caso es importante observar que si nos basamos en el tiempo del relato, se observa una importancia similar e incluso mayor, en la Casa de Adobe con respecto a la Ex-Aduana. Por otra parte, observamos los aspectos del relato, los cuales se ven reflejados en la importancia que le dieron los medios de comunicación a ciertos momentos y lugares durante la Toma de Ciudad Juárez, es decir, la mirada del reportero en este caso; y finalmente, los modos del relato, que se ven reflejados en el lugar y en la manera en los que fueron reproducidas y difundidas las fotografías en aquella época.

Sin embargo, cabe destacar lo que sugieren Todorov et al. (1970) con respecto a la diferencia que existe entre el tiempo de la escritura y el tiempo de la lectura (p. 177).

En el momento en el que se dieron los hechos, ciertos aspectos fueron relatados a través de las imágenes y el texto, principalmente en los diarios de la época, aunque también fueron tomadas algunas secuencias cinematográficas. La memoria colectiva generada en mayo de 1911 fue construida, recordando a Bergson

2 Imagen tomada de http://tramoya3.blogspot.mx/2011/03/centenario-de-la-batalla-deciudad.html (16/05/2016). 
(1896), "in the form of memory-images, all the events of our daily life as they occur in time; it neglects no detail; it leaves to each fact, to each gesture, its place and date" (p. 93).

En la actualidad, la importancia de las edificaciones aquí mencionadas ha cambiado, ya que mientras la Casa de Adobe fue relegada -a su alrededor se desarrollaron varios asentamientos irregulares integrados por familias pobres e inmigrantes-, la ExAduana continuó siendo un edificio representativo de la ciudad en el que se realizaban eventos conmemorativos sobre la Toma de Ciudad Juárez, con el objetivo de crear una memoria colectiva a partir de la repetición.

Figura 7. Imagen de la Casa de Adobe en 2013; al fondo, las torres de la refinadora Asarco (antes de su demolición). ${ }^{3}$

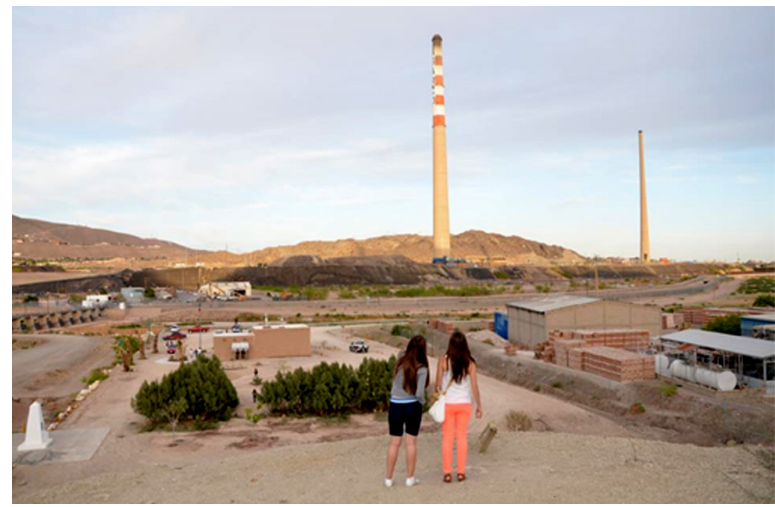

3 Imagen tomada de http://www.frontenet.com/notas/20130509/conmemoran_la_toma_ de_juarez_con_puesta_en_escena_en_la_casa_de_adobe (16/05/2013). 
Figura 8. Imagen actual del edificio de la Ex-Aduana. ${ }^{4}$

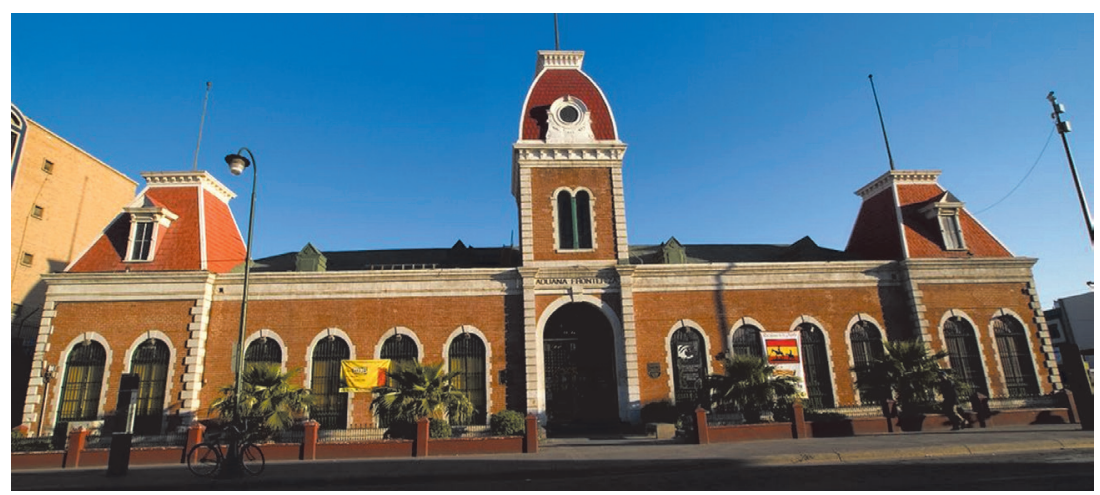

Figura 9. Imagen del evento conmemorativo de la Toma de Ciudad Juárez en $2013 .^{5}$

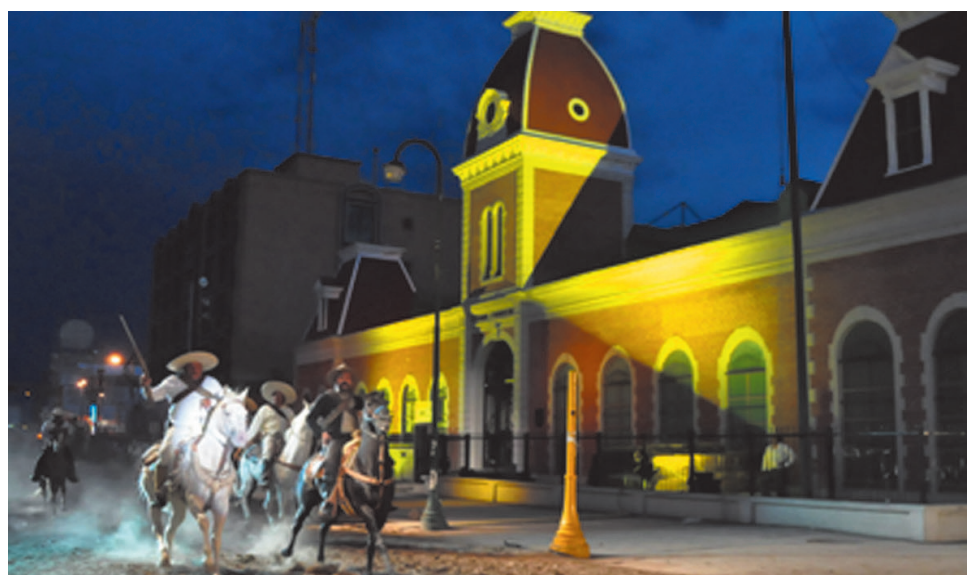

\section{CONCLUSIONES}

Podemos observar, a partir de estos ejemplos, la importancia que juegan el relato y la memoria en la construcción de nuestros imaginarios, los cuales trascienden los objetos y los espacios construyendo un mundo imaginario, a través de su papel como

4 Imagen tomada de http://www.panoramio.com/photo/2232909 (16/05/2013).

5 Imagen tomada de http://www.nortedigital.com.mx/41385/cerraran_tramo_del_pronaf__por_lla_toma_de_juarez/ (16/05/2013). 
generador de relatos. Las edificaciones generan una identidad, ya sea por sus momentos históricos, o bien, por el papel que juegan, por lo que estas se vuelven contenedoras de hechos, pasajes y momentos que se van narrando.

También cabe destacar la manera en la que estos relatos son narrados, cómo percibe los hechos quien los narra y la importancia que tiene la manera en la que son narrados, como testimonios estratificados de las dinámicas del poder. Asimismo, la importancia de qué se narra, es decir, qué es lo que se dice y qué es lo que no se dice, a qué le damos mayor importancia y con qué fin lo hacemos. En este discurso cuentan mucho el tiempo, los aspectos y los modos en los que se construye el relato.

Es importante destacar que es precisamente en Ciudad Juárez durante el movimiento revolucionario de 1910, que se generan los primeros registros fotográficos e imágenes reales, a través de una cinematografía primitiva, la cual da pauta a la construcción de estos imaginarios colectivos que facilitaron los medios para la construcción de la historia de esos momentos, de edificaciones que son el reflejo de escenarios y entornos, que reavivan expresiones, sensaciones y emociones, que se vuelven relevantes para tratar de recrear aquellos momentos para mantenerlos en la memoria, aun cuando las edificaciones desarrollen una función diferente. Al final del día, ello pasará a formar parte de nuestra memoria, tanto individual como colectiva.

\section{BIBLIOGRAFÍA}

Barthes, R. (1970). Introducción al análisis estructural de los relatos. Argentina: Tiempo Contemporáneo.

Bergson, H. (1896). Matter and Memory. Recuperado el 21 de enero de 2017, de http://www.reasoned.org/dir/lit/matter_and_memory.pdf

---- (2006). Materia y memoria: ensayo sobre la relación del cuerpo con el espíritu. Buenos Aires: Cactus. 
Flores Simental, R., Gutiérrez Roa, E., \& Vázquez Reyes, Ó. (2010). Paso del Norte en el siglo XXI: breve historia de Ciudad Juárez. México: UACJ.

Instituto Chihuahuense de la Cultura (Ichicult) (2011). La Toma de Ciudad Juárez: una historia en imágenes. Mayo de 1911. México: UACJ.

McLuhan, M. (1994). Comprender los medios de comunicación: las extensiones del ser humano. Barcelona: Paidós.

Meléndez, A., \& Bedregal, J. F. (eds.). (2009). Objeto, tiempo, espacio en la historia del diseño. México: UAM-Azcapotzalco.

Mora, C. (2014). Mito e interpretación de la Revolución mexicana: Mariátegui y Haya de la Torre. Relacso, 5(1), 1-21.

Seguí de la Riva, F. J. (2006). Arquitectura y narración. Recuperado el 15 de noviembre de 2016, de http://upcommons.upc.edu/ revistes/bitstream/2099/2308/1/IAU-00092-87.pdf

Thompson, J. B. (1998). Los media y la modernidad: una teoría de los medios de comunicación. Barcelona: Paidós.

Todorov, T., Barthes, R., Greimas, A. J., Bremond, C., Gritti, J., Morin, V., Metz, C., \& Genette, G. (1970). Las categorías del relato literario. Análisis estructural del relato. Argentina: Tiempo Contemporáneo. 